\title{
Practical considerations for therapies targeting the prostacyclin pathway
}

\author{
Harrison W. Farber ${ }^{1}$ and Wendy Gin-Sing ${ }^{2}$ \\ Affiliations: ${ }^{1}$ The Pulmonary Center, Boston University School of Medicine, Boston, MA, USA. ${ }^{2}$ Hammersmith \\ Hospital, London, UK.
}

Correspondence: Harrison W. Farber, The Pulmonary Center, Boston University School of Medicine, 72 East Concord Street, R-304, Boston, MA 02118, USA. E-mail: hfarberQbu.edu

ABSTRACT Therapies that target the prostacyclin pathway play a key role in the treatment of both earlyand late-stage pulmonary arterial hypertension, and provide significant clinical benefits for patients. A number of agents have been approved, which are administered via intravenous, subcutaneous, inhaled or oral routes. The use of these therapies is associated with practical challenges, relating to the need for uptitration and their routes of administration. We discuss here a number of measures that can be taken to support patients and healthcare professionals in order to address the complexities of using these therapies and to encourage compliance. Providing patients with timely information and education, together with practical advice on managing their medication and associated equipment, assists patients with day-to-day management of therapy. Referral to patient associations and support groups can be of further benefit. With an effective management plan and an experienced multidisciplinary team, the use of therapies that target the prostacyclin pathway can be optimised.

0

@ERSpublications

Practical support for patients and HCPs to facilitate the use of therapies that target the $\mathrm{PGI}_{2}$ pathway in PAH http://ow.ly/468S305Dl6m

\section{Introduction}

The prostacyclin (prostaglandin $\mathrm{I}_{2}\left(\mathrm{PGI}_{2}\right)$ ) pathway is an important therapeutic target in pulmonary arterial hypertension $(\mathrm{PAH})$. Reduced levels of $\mathrm{PGI}_{2}$ are associated with pathogenic changes within the lung vasculature $[1,2]$ and therapies that aim to restore $\mathrm{PGI}_{2}$ signalling have been shown to play a key role in PAH management [3]. Evidence to support the use of therapies targeting the $\mathrm{PGI}_{2}$ pathway was first generated in the 1990s when intravenous epoprostenol, a synthetic version of $\mathrm{PGI}_{2}$, was demonstrated to provide symptomatic and haemodynamic benefits and to improve survival $[4,5]$. As a result, epoprostenol was the first drug to be approved for PAH [5]. A number of other therapies targeting the $\mathrm{PGI}_{2}$ pathway have since become available, administered by i.v. [6, 7], subcutaneous [6], inhaled [8-10] or oral [11-15] routes (figure 1 and table 1 ) [8, 16-26].

These therapies have demonstrated significant clinical benefits for a broad population of PAH patients, and play a key role in the treatment of both early- and late-stage disease. There are, however, some practical challenges associated with the use of these agents, which may contribute to their underuse in clinical practice $[27,28]$. The challenges can be broadly grouped into two aspects. Firstly, these drugs require up-titration to find the clinically appropriate dose for each individual patient. Secondly, for some of these drugs, the physicochemical properties require that they are administered i.v., s.c. or by the inhalation route. Due to the importance of $\mathrm{PGI}_{2}$-targeting therapies, it is critical for the wellbeing of $\mathrm{PAH}$

Editorial comment in Eur Respir Rev 2016; 25: 361-363.

Received: Aug 182016 | Accepted after revision: Oct 232016

Conflict of interest: Disclosures can be found alongside this article at err.ersjournals.com

Provenance: The European Respiratory Review received sponsorship from Actelion Pharmaceuticals Ltd, Allschwil, Switzerland, for the publication of this peer-reviewed article.

Copyright CERS 2016. ERR articles are open access and distributed under the terms of the Creative Commons Attribution Non-Commercial Licence 4.0. 


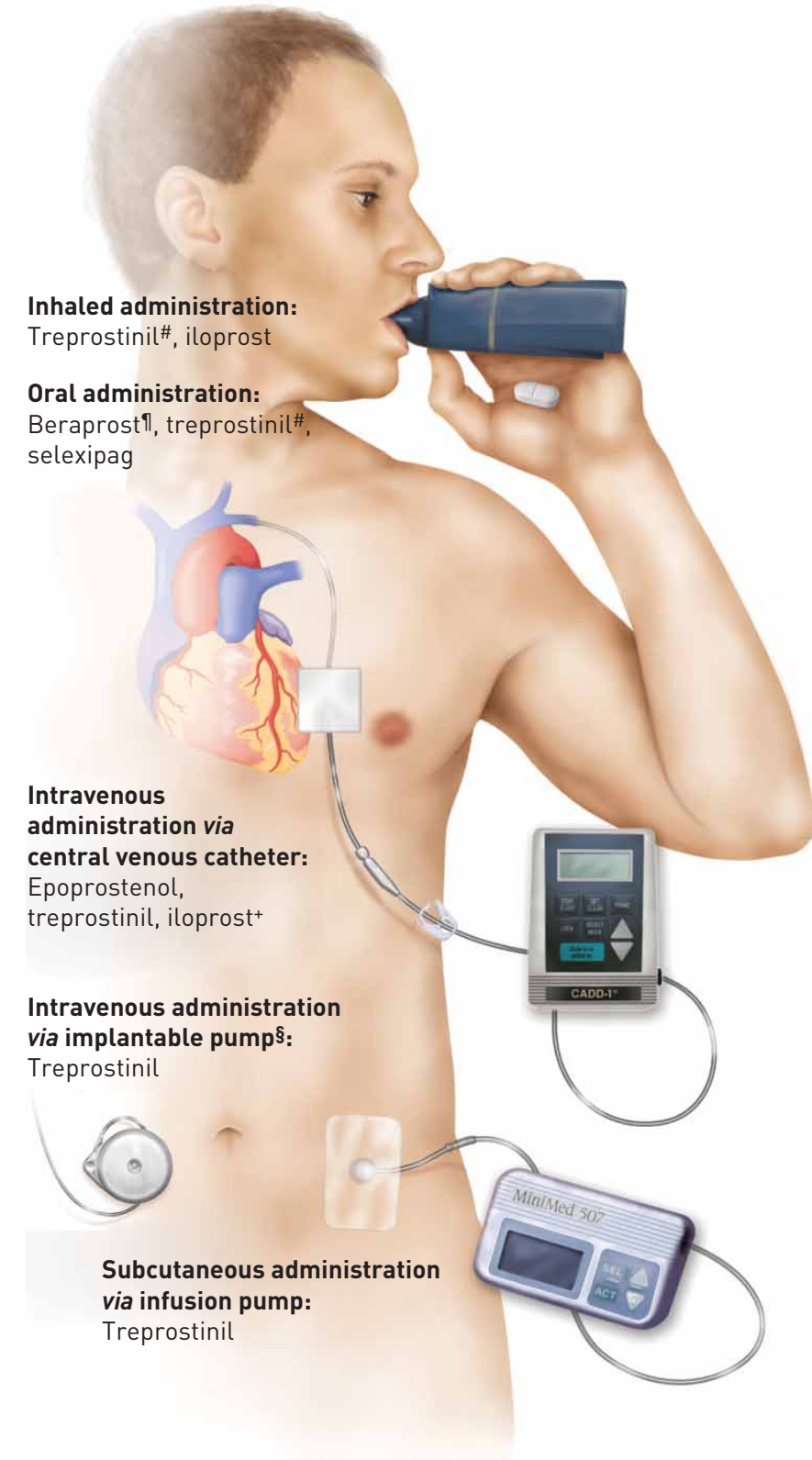

FIGURE 1 Drugs that target the prostacyclin pathway and their routes of administration. \#: approved only by the US Food and Drug Administration; "1: approved only in Japan and South Korea; ${ }^{+}$: approved only in New Zealand; § : this pump is under investigation and is not approved in the USA or Europe. Reproduced from [16] with permission from the publisher.

patients that both patients and healthcare professionals (HCPs) are comfortable with their use. In this review, we describe practical ways to facilitate the use of these therapies in $\mathrm{PAH}$, in order to support HCPs and patients. We draw on our own clinical experience, the experience of many other pulmonary hypertension $(\mathrm{PH})$ experts and an expanding literature in this field.

\section{Up-titration of therapies}

Therapies that target the $\mathrm{PGI}_{2}$ pathway require up-titration; the reason for this is two-fold. Firstly, the efficacious dose varies between individuals and the up-titration process allows the clinically appropriate dose for each patient to be achieved. Secondly, up-titration allows patients to initiate therapy at a low dose and increase it gradually, whilst managing potential side-effects associated with activation of the $\mathrm{PGI}_{2}$ pathway.

Up-titration is performed according to one of three approaches: up-titration to the highest tolerated dose, up-titration to a pre-defined target dose or up-titration until a clinical response is observed. The approach 
TABLE 1 Overview of therapies targeting the prostacyclin pathway

\begin{tabular}{|c|c|c|c|c|c|c|c|c|c|c|c|c|}
\hline \multirow[t]{4}{*}{$\mathrm{PGI}_{2}$ therapy } & \multicolumn{2}{|c|}{ Approval } & \multirow{4}{*}{$\begin{array}{l}\text { WHO FC } \\
\text { indication }\end{array}$} & \multirow[t]{4}{*}{ Mode of administration } & \multirow[t]{4}{*}{ Frequency of administration } & \multirow[t]{4}{*}{ Half-life } & \multirow{2}{*}{\multicolumn{6}{|c|}{$\begin{array}{l}\text { ESC/ERS class of recommendation" }{ }^{\#} \text { and level } \\
\text { of evidence for use as monotherapy" }[3,17]\end{array}$}} \\
\hline & \multirow[t]{3}{*}{ Europe } & \multirow[t]{3}{*}{ USA } & & & & & & & & & & \\
\hline & & & & & & & \multicolumn{2}{|c|}{ WHO FC II } & \multicolumn{2}{|c|}{ WHO FC III } & \multicolumn{2}{|c|}{ WHO FC IV } \\
\hline & & & & & & & Class & Level & Class & Level & Class & Level \\
\hline Flolan [18] (epoprostenol) & + & + & III-IV & Intravenous & Continuous & $<6 \min [24]$ & & & 1 & A & 1 & A \\
\hline $\begin{array}{l}\text { Veletri' }[19,20] \\
\quad \text { (epoprostenol) }\end{array}$ & + & + & III-IV & Intravenous & Continuous & & & & & & & \\
\hline $\begin{array}{l}\text { Remodulin }[6,21] \\
\text { (treprostinil) }\end{array}$ & $+\#$ & + & II-IV & Intravenous & Continuous & $34 \min [25]$ & & & Ila & C & Ilb & C \\
\hline $\begin{array}{l}\text { Remodulin }[6,21] \\
\text { (treprostinil) }\end{array}$ & $+\#$ & + & II-IV & Subcutaneous & Continuous & $85 \min [25]$ & & & 1 & B & $\mathrm{llb}$ & c \\
\hline Tyvaso [8] (treprostinil) & - & + & III & Inhaled & $\begin{array}{c}4 \text { times per day, with } \\
\text { each inhalation taking up to } \\
3 \text { min }[8,26]\end{array}$ & NA & & & 1 & B & Ilb & C \\
\hline $\begin{array}{r}\text { Orenitram [11] } \\
\text { (treprostinil) }\end{array}$ & - & + & $\| I-I I I$ & Oral & 2-3 times per day & $3-4 \mathrm{~h}[24]$ & & & Ilb & B & & \\
\hline Ilomedin ${ }^{\S}$ [7] (iloprost) & - & - & III-IV & Intravenous & Over $6 \mathrm{~h}$ daily & $20-25 \min [24]$ & & & Ila & C & $\mathrm{Ilb}$ & C \\
\hline Ventavis $[9,10]$ (iloprost) & + & + & III-IV & Inhaled & $\begin{array}{c}\text { 6-9 times per day, with } \\
\text { each inhalation taking } \\
\text { 3-10 min, depending on } \\
\text { dose and nebuliser } \\
\text { device [9] }\end{array}$ & & & & 1 & B & $\mathrm{Ilb}$ & C \\
\hline Dorner $^{f}[15]$ (beraprost) & - & - & NA & Oral & 3-4 times per day & $45 \min [24]$ & & & Ilb & B & & \\
\hline Uptravi $[12,13]$ (selexipag) & + & + & II-III & Oral & 2 times per day & $6.2-13.5 h^{\text {กิ1 [12] }}$ & I & B & 1 & B & & \\
\hline
\end{tabular}

$\mathrm{PGI}_{2}$ : prostaglandin $\mathrm{I}_{2}$ (prostacyclin); WHO FC: World Health Organization functional class; ESC: European Society of Cardiology; ERS: European Respiratory Society; NA: not available. \#: I, evidence and/or general agreement that a given treatment or procedure is beneficial, useful or effective; II, conflicting evidence and/or a divergence of opinion about the usefulness/ efficacy of the given treatment or procedure; Ila, weight of evidence/opinion is in favour of usefulness/efficacy; Ilb, usefulness/efficacy is less well established by evidence/opinion; III, evidence or general agreement that the given treatment or procedure is not useful/effective and in some cases may be harmful. ": A, data derived from multiple randomised clinical trials or meta-analyses; B, data derived from a single randomised clinical trial or large nonrandomised studies; C, consensus of opinion of the experts, and/or small studies, retrospective studies or registries. ${ }^{+}$: known as Caripul in some countries. ${ }^{\S}$ : approved in New Zealand. ${ }^{\prime}$ : approved in Japan and South Korea [22], a modified-release version is available (Careload [14] and Berasus [23]) and can be administered twice per day. "\#: approved in the European Union, except Ireland, Spain and the UK [21]. "१?: active selexipag metabolite. 
TABLE 2 Protocols for up-titration of therapies that target the prostacyclin pathway

$\begin{array}{llll}\mathrm{PGI}_{2} \text { therapy } & \text { Initiation protocol } & \text { Up-titration protocol } & \begin{array}{l}\text { Target dose and } \\ \text { dosing frequency }\end{array}\end{array}$

Epoprosteno

Flolan [18]

$$
\begin{aligned}
& \text { Short-term: } \\
& 2 \mathrm{ng} \cdot \mathrm{kg}^{-1} \cdot \mathrm{min}^{-1} \text {; if this is not } \\
& \text { tolerated, a lower dose } \\
& \text { which is tolerated should be } \\
& \text { identified } \\
& \text { Long-term: } 4 \mathrm{ng} \cdot \mathrm{kg}^{-1} \cdot \mathrm{min}^{-1} \\
& \text { less than MTD identified } \\
& \text { during short-term dosing; if } \\
& \text { MTD } \leqslant 5 \mathrm{ng} \cdot \mathrm{kg}^{-1} \cdot \mathrm{min}^{-1} \text {, } \\
& \text { infusion should be started at } \\
& \text { half the MTD }
\end{aligned}
$$

\section{Treprostinil}

Remodulin i.v./s.c. [6] $\quad 1.25 \mathrm{ng} \cdot \mathrm{kg}^{-1} \cdot \mathrm{min}^{-1}$ for patients new to $\mathrm{PGI}_{2}$ infusion therapy; reduce to $0.625 \mathrm{ng} \cdot \mathrm{kg}^{-1} \cdot \mathrm{min}^{-1}$ if $1.25 \mathrm{ng} \cdot \mathrm{kg}^{-1} \cdot \mathrm{min}^{-1}$ is not tolerated

Tyvaso [8]

\section{3 breaths $(18 \mu \mathrm{g})$ per} treatment session; if 3 breaths are not tolerated, reduce to 1 or 2 breaths and subsequently increase to 3 breaths as tolerated
Increased by increments

$$
\begin{aligned}
& \text { of } 2 \mathrm{ng} \cdot \mathrm{kg}^{-1} \cdot \mathrm{min}^{-1} \text { every } \\
& 15 \mathrm{~min} \text { or longer }
\end{aligned}
$$

of $2 \mathrm{ng}^{-1} \cdot \mathrm{min}^{-1}$ ints

$15 \mathrm{~min}$ or longer $\#$

Until maximum

haemodynamic

benefit or

dose-limiting

pharmacological

effects

Administered as

continuous infusion

Until maximum

haemodynamic

benefit or

dose-limiting

pharmacological

effects are elicited $\#$

Administered as

continuous infusion $\#$, "

Based on clinical

response

prescribing information suggests increments of

$1.25 \mathrm{ng} \cdot \mathrm{kg}^{-1} \cdot \mathrm{min}^{-1}$ per week for

the first 4 weeks of treatment

and increments of

$2.5 \mathrm{ng} \cdot \mathrm{kg}^{-1} \cdot \mathrm{min}^{-1}$ per week after

4 weeks of up-titration. In

clinical practice, the dose is

usually increased more quickly, aiming to reach $20 \mathrm{ng} \cdot \mathrm{kg}^{-1} \cdot \mathrm{min}^{-}$ after 4 weeks [29]

Increase by an additional 3 breaths at 1-2-week intervals

9 breaths $(54 \mu \mathrm{g})$ per treatment session, 4 times daily
Increase: by

$1-2 \mathrm{ng} \cdot \mathrm{kg}^{-1} \cdot \mathrm{min}^{-1}$ at

intervals sufficient to

allow assessment of

clinical response;

these intervals

should be at least

15 min" $^{\text {" }}$

Decrease: gradually in

$2 \mathrm{ng} \cdot \mathrm{kg}^{-1} \cdot \mathrm{min}^{-1}$

decrements every 15

min or longer until

dose-limiting effects

resolve ${ }^{\pi}$

ncrease: by

1-2 $\mathrm{ng} \cdot \mathrm{kg}^{-1} \cdot \mathrm{min}^{-1}$ at

intervals sufficient to

allow assessment of

clinical response;

these intervals

should be at least

15 min" $^{\text {" }}$

Decrease: gradually in

$2 \mathrm{ng} \cdot \mathrm{kg}^{-1} \cdot \mathrm{min}^{-1}$

decrements every

15 min or longer

until dose-limiting

effects resolve ${ }^{\pi}$

Short-term dosing should be conducted in a hospital with adequate

resuscitation equipment $\#$

Abrupt withdrawal of Flolan or sudden large reductions in infusion rates should be avoided due to the risk of potential fatal rebound effects ${ }^{\text {I }}$

Except in life-threatening situations,

infusion rates should be adjusted only under the direction of a physician"

Short-term dosing should be conducted in a hospital with adequate resuscitation equipment ${ }^{\#}$

Abrupt withdrawal of Veletri or sudden large reductions in infusion rates should be avoided due to the risk of potential fatal rebound effects ${ }^{\text {I }}$

Except in life-threatening situations, infusion rates should be adjusted only under the direction of a physician"

NA

Avoid abrupt cessation

In the case of mild to moderate hepatic insufficiency, decrease initial dose to $0.625 \mathrm{ng} \cdot \mathrm{kg}^{-1} \cdot \mathrm{min}^{-1}$

If transitioning from i.v. epoprostenol, the dose should be increased while simultaneously reducing the dose of i.v. epoprostenol. The transition to Remodulin should take place in the hospital with constant observation of response

Titrate slowly in patients with hepatic or renal insufficiency 
TABLE 2 Continued

\begin{tabular}{|c|c|c|c|c|c|}
\hline $\mathrm{PGI}_{2}$ therapy & Initiation protocol & Up-titration protocol & $\begin{array}{l}\text { Target dose and } \\
\text { dosing frequency }\end{array}$ & Dose adjustments & Additional comments \\
\hline Orenitram [11] & $\begin{array}{l}0.25 \mathrm{mg} \text { twice or } 0.125 \mathrm{mg} \\
\text { three times daily }\end{array}$ & $\begin{array}{l}\text { Increase by } 0.25 \text { or } 0.5 \mathrm{mg} \text { twice } \\
\text { daily or } 0.125 \mathrm{mg} \text { three times } \\
\text { daily, not more than every } \\
3-4 \text { days as tolerated }\end{array}$ & $\begin{array}{l}\text { MTD is determined by } \\
\text { tolerability; increase } \\
\text { to highest MTD } \\
\text { Administered twice or } \\
\text { three times daily }\end{array}$ & $\begin{array}{l}\text { If intolerable } \\
\text { pharmacological } \\
\text { effects occur, } \\
\text { decrease the dose in } \\
\text { increments of } \\
0.25 \mathrm{mg}\end{array}$ & $\begin{array}{l}\text { If transitioning from i.v./s.c. Remodulin, } \\
\text { the dose should be increased while } \\
\text { simultaneously decreasing the i.v./s.c. } \\
\text { infusion rate } \\
\text { In the case of mild hepatic impairment, } \\
\text { initiate at } 0.125 \mathrm{mg} \text { twice daily, } \\
\text { increase at } 0.125 \mathrm{mg} \text { twice daily every } \\
3-4 \text { days } \\
\text { Avoid abrupt discontinuation }\end{array}$ \\
\hline \multicolumn{6}{|l|}{ Iloprost } \\
\hline Ilomedin [7] & $0.5 \mathrm{ng} \cdot \mathrm{kg}^{-1} \cdot \mathrm{min}^{-1}$ for $30 \mathrm{~min}$ & $\begin{array}{l}\text { Increase by } 0.5 \mathrm{ng} \cdot \mathrm{kg}^{-1} \cdot \mathrm{min}^{-1} \\
\text { in } 30-\mathrm{min} \text { intervals up to } \\
2.0 \mathrm{ng} \cdot \mathrm{kg}^{-1} \cdot \mathrm{min}^{-1}\end{array}$ & $\begin{array}{l}\text { MTD within the range of } \\
0.5-2.0 \mathrm{ng} \cdot \mathrm{kg}^{-1} \cdot \mathrm{min}^{-1} \\
\text { Administered as an } \\
\text { i.v. infusion over } 6 \mathrm{~h} \\
\text { daily }\end{array}$ & $\begin{array}{l}\text { If undesirable } \\
\text { side-effects occur, } \\
\text { the infusion rate } \\
\text { should be reduced } \\
\text { until the tolerable } \\
\text { dose is found }\end{array}$ & $\begin{array}{l}\text { Should only be used under strict } \\
\text { monitoring in hospitals or outpatient } \\
\text { clinics with adequate facilities }\end{array}$ \\
\hline Ventavis [9] & $2.5 \mu \mathrm{g}$ per treatment session & $\begin{array}{l}\text { Increase to } 5 \mu \mathrm{g} \text { if initial dose is } \\
\text { well tolerated }\end{array}$ & $\begin{array}{l}\text { Administered 6-9 times } \\
\text { daily, depending on } \\
\text { individual need and } \\
\text { tolerability, up to } 5 \mu \mathrm{g} \\
\text { per treatment session }\end{array}$ & $\begin{array}{l}\text { In cases of poor } \\
\text { tolerability of the } \\
5 \mu \mathrm{g} \text { dose, the dose } \\
\text { should be reduced to } \\
2.5 \mu \mathrm{g} \text { per treatment } \\
\text { session }\end{array}$ & $\begin{array}{l}\text { In patients with hepatic impairment, } \\
\text { special caution should be exercised } \\
\text { during initial dose titration }\end{array}$ \\
\hline \multicolumn{6}{|l|}{ Beraprost } \\
\hline Dorner [15] & $20 \mu \mathrm{g}$ three times daily & $\begin{array}{l}\text { The dosage may be increased } \\
\text { gradually according to symptoms }\end{array}$ & $\begin{array}{l}\text { Maximum daily } \\
\text { dose should not } \\
\text { exceed } 9 \text { tablets } \\
(180 \mu \mathrm{g}) \\
\text { If the dose is increased, } \\
\text { it may be taken } \\
3-4 \text { times daily }\end{array}$ & NA & \\
\hline \multicolumn{6}{|l|}{ Selexipag } \\
\hline Uptravi [12] & $200 \mu \mathrm{g}$ twice daily, $12 \mathrm{~h}$ apart & $\begin{array}{l}\text { Increased in increments of } 200 \mu \mathrm{g} \\
\text { twice daily, at weekly intervals }\end{array}$ & $\begin{array}{l}\text { MTD (can range from } \\
200 \text { to } 1600 \mu \mathrm{g} \text { twice } \\
\text { daily) } \\
\text { Administered twice daily }\end{array}$ & $\begin{array}{l}\text { If the patient reaches a } \\
\text { dose that cannot be } \\
\text { tolerated, the dose } \\
\text { should be reduced to } \\
\text { the previous dose } \\
\text { level }\end{array}$ & $\begin{array}{l}\text { At the beginning of treatment, and at } \\
\text { each up-titration step, it is } \\
\text { recommended to take the first dose in } \\
\text { the evening } \\
\text { If treatment is missed for } 3 \text { days or } \\
\text { more, Uptravi should be re-started at } \\
\text { a lower dose and then up-titrated } \\
\text { Withdrawal of Uptravi should be done } \\
\text { gradually, while an alternative therapy } \\
\text { is introduced }\end{array}$ \\
\hline
\end{tabular}


varies depending on the drug (table 2 [29]). Selexipag is an example of a therapy that is up-titrated to the individual patient's highest tolerated dose, up to a maximum of $1600 \mu \mathrm{g}$ twice daily [12, 13]. This individualised dosing strategy was employed in the GRIPHON study, in which selexipag showed consistent efficacy when patients were grouped according to whether they received a low, medium or high dose of the drug [30]. These data confirm the validity of titrating to the highest tolerated dose in order to find the efficacious dose [30]. In contrast, inhaled treprostinil is up-titrated with the aim of reaching a target maintenance dosage of nine breaths $(54 \mu \mathrm{g}$ treprostinil) per treatment session, as tolerated [8]. Despite a lack of efficacy data, doses higher than the approved dose of $54 \mu \mathrm{g}$ treprostinil have been administered in some cases [31]. Intravenous prostanoids and s.c. treprostinil are examples of therapies that are usually up-titrated based on clinical response $[6,7,18]$. Clinical response can be assessed using multiple parameters, including haemodynamics, exercise tolerance, World Health Organization functional class (WHO FC), echocardiography and brain natriuretic peptide level. The reasons for the different dose responses between patients are not known, although a number of hypotheses exist. IP prostacyclin receptor density varies among patients and may influence the individual dose required [32-34], as may differences in receptor kinetics or drug metabolism between patients.

Since up-titration is a requirement for the use of therapies that target the $\mathrm{PGI}_{2}$ pathway, steps can be taken to optimise the process for HCPs and patients. These include taking a flexible approach to the up-titration process, managing side-effects, and providing education and support to patients.

Protocols for up-titration allow flexibility, enabling the process to be tailored according to the needs and preferences of the patient and the treating staff. Titration schemes may be adapted depending on factors such as clinical response, side-effects and experience of the HCP. There is also flexibility for certain therapies regarding dosing frequency; modifying the dosing frequency may help to facilitate successful up-titration [11]. For example, it has been hypothesised that increasing the dosing frequency of oral treprostinil from twice to three times a day improves the pharmacokinetic profile of the drug by reducing peak to trough fluctuations. This may reduce the frequency of dose-limiting side-effects [35-37]; although this has not yet been proven in a randomised controlled trial, it is being evaluated in the FREEDOM-EV trial, which is currently enrolling patients [38].

There is also scope for flexibility regarding where the up-titration process is initiated for certain drugs. Inhaled and oral therapies may in some cases be started at home with adequate supervision and training by a PAH specialist. Subcutaneous treprostinil can be started at home for some patients, while others require hospitalisation for a few days [39] if their disease is less stable and/or side-effects are more severe. In contrast, i.v. therapies must always be initiated in a hospital setting with experienced personnel and strict patient monitoring $[6,7,18]$.

Prostanoid therapies are associated with several side-effects, including headache, diarrhoea, flu-like symptoms, jaw pain, muscle spasm, flushing and nausea [40]. During up-titration, side-effects may in some cases prevent a patient from reaching an efficacious dose. Informing patients in advance about common side-effects can help to prepare them for the up-titration process. Patients can be reassured that side-effects are more frequent during the up-titration phase and that once the appropriate dose has been reached, the side-effects will improve. Compliance can be improved by explaining to patients that side-effects are often unavoidable to reach an appropriate dose. HCPs can also provide support by advising patients that the dose can be decreased or up-titrated more slowly if side effects are not tolerated. This allows patients to gain a sense of control during the up-titration process.

A number of steps can be taken to proactively manage side-effects. Increasing the dose of i.v. prostanoids more aggressively during initiation in the hospital enables patients to experience side-effects in a supportive environment before they are discharged. Providing patients with a supply of analgesics, antiemetics and antidiarrhoeal agents to take home allows them to promptly manage side-effects as they develop. Patients may also take these agents before dose increases if headaches, nausea or diarrhoea have been a problem previously, or to avoid pain/nausea memory.

Despite the importance of up-titrating therapies to an efficacious dose, there may be a reluctance to increase the dose of some therapies. This can be illustrated by s.c. treprostinil, where there may be a misconception amongst patients and many HCPs that higher doses cause greater infusion site pain. To counteract this misconception, patients can be informed that infusion site pain is not dose-dependent [41] and higher doses are needed to achieve efficacy [42].

The up-titration process requires patients to be well-informed, with clear explanations about what is involved and that side-effects will abate. By providing support and managing their expectations, patients can be empowered to be involved in their own self-care. Patient engagement and the benefits of involving patients, families and carers in decisions about patient care are discussed further by GAARUP et al. [43] in this issue of the European Respiratory Review. 
Various educational materials on therapies targeting the $\mathrm{PGI}_{2}$ pathway and the up-titration process are available to patients, such as DVDs, websites and printed information. Patient associations have developed a wealth of information around $\mathrm{PAH}$ (e.g. www.ourphlibrary.com). Patients receiving i.v. therapies can also access drug-specific web portals that have been developed by pharmaceutical companies to provide information and help with troubleshooting. Using these resources to highlight the benefits of therapy aids motivation to persevere with up-titration. Patients can also learn from the experience of others through patient-directed videos, meeting patient volunteers and attending support groups organised by patient associations. In addition, there are patient chat rooms, including those associated with the Pulmonary Hypertension Association [44]. Introduction to a buddy/patient support system matches individuals to a $\mathrm{PAH}$ patient of similar demographics who has been successfully established on therapy, allowing new patients to learn from those with more experience.

To address the complexities of titrating $\mathrm{PGI}_{2}$-targeting therapies, patients require support from a multidisciplinary team of HCPs. Initiation of these therapies should also be conducted under the guidance of an experienced pulmonary hypertension centre. Successful up-titration not only depends on patient education, but also HCP education, experience and knowledge, both in the hospital and community. As many of the patients will live a significant distance away from their pulmonary hypertension centre, it is advisable that the local community nurses and physicians are aware of possible side-effects and know whom to contact for specialist advice. Nurses play a central role in the multidisciplinary team [45, 46], managing patient expectations, and working with patients to set realistic, measurable and achievable treatment goals [45]. These goals may relate to the patient's symptoms, functional capacity or mortality. Personal treatment goals, such as reaching a particular milestone or life event (e.g. a family wedding), may improve motivation to continue with the titration process. Reassurance and support can be provided to patients by HCPs through regular follow-up, both over the phone and during clinic visits, and provision of emergency out-of-hours contacts. This support is beneficial to the patient, not only during the up-titration phase but also during long-term treatment.

Once patients on therapies that target the $\mathrm{PGI}_{2}$ pathway have reached their clinically appropriate dose, it is essential they are formally assessed at regular intervals to monitor their clinical status [3]. For those receiving i.v. and s.c. prostanoids, the intervals between clinic visits are usually shorter since these patients tend to be more unwell, at least initially, and need more attentive follow-up. Tolerance to prostanoids may develop during long-term use [47]. As such, further up-titration may be needed after variable periods of time on the previous efficacious dose. In addition, dose increases may be needed due to disease progression. Regular patient assessment ensures that any necessary dose adjustments can be made in a timely manner.

\section{Considerations relating to the route of administration}

There are various challenges related to the routes of administration of therapies targeting the $\mathrm{PGI}_{2}$ pathway. Taking appropriate action to address these issues is crucial to minimise the impact on patients and carers, and to optimise the benefits that these therapies offer (table 3) [48-50].

\section{Intravenous administration}

Several i.v. therapies are approved for the treatment of PAH: epoprostenol $[18,19,26]$, treprostinil $[6]$ and iloprost [7] (table 1). The European Society of Cardiology/European Respiratory Society (ESC/ERS) guidelines cite different levels of recommendation and evidence for each therapy $[3,17]$, with epoprostenol having the highest level (IA) in patients with WHO FC III or IV disease. Intravenous prostanoids require continuous infusion via a central venous catheter due to their short half-lives $[6,18,39]$. This route of administration is complex, and can present challenges for patients, carers and HCPs. In light of this, and given the clear benefits of i.v. prostanoids in PAH treatment, steps must be taken to support patients and HCPs (table 3).

Prior to starting therapy, patients can be introduced to the i.v. delivery system to help them understand what treatment will entail. As patients need to wear a pump continuously once on therapy $[6,18]$, providing patients with practice pumps and equipment to take home allows them to get used to wearing and sleeping with the equipment. Only pumps that meet the stringent safety criteria detailed in the prescribing information should be used $[6,26,51]$. For the majority of patients, a battery-operated ambulatory pump is used; an implantable pump for delivery of i.v. treprostinil is currently under investigation. The patient is expected to participate in the preparation of the infusion; however, learning the reconstitution process can be lengthy and complicated $[6,7,18,52]$, especially when the patient is unfamiliar with the equipment. Thus, patients will benefit from receiving clear practical advice on this. Practical training allows clinical staff to observe patients, and to assess and identify potential issues with the physical, emotional and cognitive ability of the patient to manage i.v. therapy [39]. Staff should consider whether the patient has a suitable home environment and social support system, including a support 
TABLE 3 Practical considerations and steps to aid patients on intravenous, subcutaneous, inhaled or oral therapies

Mode of administration

Intravenous

Subcutaneous

Inhaled

Oral

All routes

\section{Practical considerations and steps}

Provide practice equipment/pumps prior to linking infusion

Provide an introduction/education on the i.v. delivery system, the need

for a central venous catheter and the up-titration procedure

Patient participation in infusion preparation

Patient education for managing medication at home and care of $i . v$. line and sterility

Provide patients with a well-defined care plan on hospital discharge, including management of side-effects

Provide advice on what to do in case of pump malfunction or a compromised i.v. line

Provide advice on practical matters on living with an i.v. line (e.g. showering) Inform local emergency services about the patient's medication in case the patient needs to be seen urgently

Use of thermostable epoprostenol [48]

Dry siting of the infusion cannula [49]

Flexibility about when the site is changed [49]

Analgesics [39]

Patient education on what to do in case of infusion system malfunction, and the need to carry spare equipment and drug

Educate patients on how to use and look after the devices

Written materials including brochures and tools to aid compliance

Medication reminders through alarms or apps on smartphones

InSight training devices to reinforce effective breathing patterns and check adherence [50]

Ensure that the patient understands the basic function of the medication, the importance of regular dosing and what to do if a dose is late or missed

Support for management of their side-effects

Support and tools to aid compliance

Medication reminders through alarms or apps on smartphones

Ensure that the patient understands the basic function of the medication, the importance of regular dosing and what to do if a dose is late or missed

Education on the up-titration process

Patient associations/support groups

Written materials, DVDs and online information

person committed to assisting with care of the infusion if the patient is unable to do so [39, 45]. A specialist team of PAH physicians and nurses is required to deal with the complexities of i.v. therapy [39].

Placement and removal of the central venous catheter may require surgery under local anaesthesia and hospitalisation $[6,53]$, although it is sometimes performed as an outpatient procedure. Once the infusion has been set up and the patient is ready to be discharged, it is essential that a well-defined care plan is in place. Patients also benefit from receiving written materials [54] and other sources of information, such as DVDs and online resources.

Intravenous administration is associated with a risk of catheter occlusion, venous thrombosis [39, 47] or thromboembolism [39], line infections [39], and catheter-related sepsis [18, 55]. Educating patients on how to care for their i.v. line is therefore important. Patients must be taught how to maintain sterile conditions when preparing infusion cassettes and syringes, and of the need to keep the cannula insertion site clean and dry. A solution of $2 \%$ chlorhexidine in $70 \%$ isopropyl alcohol can be used to clean the site [56]; it should be allowed to dry completely before applying a waterproof dressing. Risk of line infection can be reduced by using single-lumen rather than double-lumen catheters [57, 58], and by using closed-hub systems with protected connections [59-61]. Early recognition of potential signs of infection is essential [62], as sepsis from line infections can be fatal. Cases of line/tunnel infection should be treated as a medical emergency using i.v. antibiotics, with peripheral blood cultures sent for investigation and the existing line promptly removed once alternative i.v. access has been achieved. Less serious side-effects of i.v. administration, such as local skin reactions to dressings, may also occur. Testing alternative dressings on the underside of the forearm allows sensitivity to be checked prior to applying the dressing to the infusion site, and sterile application of barrier films below the dressing may help. In some cases, referral to a dermatologist may be needed. 
Serious side-effects may occur on interruption or withdrawal of i.v. prostanoids $[4,18]$, which can result from pump malfunctions or if the line is erroneously compromised. A compromised line can lead to cardiovascular collapse [63], which in our experience, can occur within minutes, although this complication is exceedingly rare, especially with appropriate patient education. In the current era, the risk of i.v. infusion interruption leading to fatal side-effects may be lower than it was previously, as an increasing number of patients are now taking an endothelin receptor antagonist and/or phosphodiesterase5 inhibitor, in addition to an i.v. prostanoid [64]. Nevertheless, patients must be taught what to do if treatment interruption occurs. It may be helpful to provide patients with information to pass on to their local HCP and emergency facilities regarding how to manage i.v. prostanoids. Arranging for the patient to be reviewed in their local hospital allows a clear management plan to be put in place in case of an emergency. Instructing personnel to never turn off the pump is crucial, even in cases of symptomatic hypotension. Information can be attached to the pump itself detailing what to do in an emergency and listing the contact details of the PAH specialist. Instructing HCPs and local emergency personnel not to use the central line to administer other medications is also important, as this can result in a bolus dose of prostanoids and side-effects related to over-dosing, such as hypotension. Patients are encouraged to be assertive to prevent catheters from being used for anything other than prostanoid administration.

Intravenous prostanoids can affect physical, social and emotional aspects of the patient's life, and also the lives of family and close friends. Causes of physical discomfort associated with i.v. therapies include the ice packs that need to be used with nonthermostable epoprostenol. These can be avoided by using room temperature-stable epoprostenol $[19,26,48]$, which negates the need for frozen gel packs and permits less frequent cassette changes. It also improves convenience by allowing patients to prepare their infusions ahead of time and store the cassettes for up to 8 days before use. Patients on temperature-stable epoprostenol who meet specific criteria may qualify for a programme where the speciality pharmacy ships seven fully-prepared cassettes on a weekly basis to the patient's home. This avoids the step of the patient or carer having to prepare the medicine. It is, however, essential that the patient and carer can prepare the infusion in an emergency situation, and that checks of this capacity are made on a regular basis by their HCPs. Physical discomfort can also be caused by the i.v. line itself. For example, patients may have discomfort when driving a car due to the seatbelt rubbing on the tunnelled line. While i.v. prostanoid therapies offer improvement in clinical status and exercise tolerance, physical day-to-day activities may be limited. Practicalities of how to undertake activities such as showering, sport or sexual intercourse while wearing a pump need to be considered. Patients benefit from practical advice, preferably in written form [54], on how to live with the i.v. line, such as how to shower using waterproof dressings.

Patients need adequate time and a suitable place to prepare infusions, which may affect social and work activities. Proximity to a hospital and PAH specialist is a consideration in case of pump malfunctions. When travelling, patients need to take spare equipment and pumps, requiring extra luggage capacity, and should carry documentation to allow them to take their equipment and solutions through airport security. Intravenous therapies can also impact the emotional wellbeing of the patient. The requirement to wear a pump can be a reminder of being ill and affect the patient's confidence, causing difficulties when forming personal relationships. There may be intimacy and body image concerns, especially for young patients, who may worry about how to conceal the pump in their clothing. Empathetic HCPs and referral of patients to patient associations and support groups can help to address the physical, social and emotional aspects of using i.v. therapies. Some patients may also benefit from professional psychological counselling. It is important to acknowledge that i.v. therapy leads to added responsibility for families and carers, and that this can also impact their emotional and social wellbeing.

\section{Subcutaneous administration}

Subcutaneous treprostinil was first approved for use as a PAH treatment in 2002 [6] and in the current ESC/ERS guidelines it is recommended for use in patients in WHO FC III or IV [3, 17] (table 1). Subcutaneous treprostinil is administered as a continual infusion via a s.c. catheter [6]. It has a longer half-life than epoprostenol [62] and as a result, the risk of haemodynamic compromise within a short period of time due to rebound pulmonary constriction appears to be lower. It is available in pre-mixed vials $[6,65]$, is stable at room temperature and can be infused continuously for $72 \mathrm{~h}$ without the need for ice packs $[6,62]$. Subcutaneous therapies do not require central venous access, utilise only a small syringe pump, and have a low risk of bacteraemia, catheter or venous thrombosis, and thromboembolism [39].

Although the s.c. mode of administration offers advantages, the delivery of a continuous parenteral infusion is not without practical challenges. Infusion site pain and reaction were the most common adverse reactions reported in clinical trials, occurring in $85 \%$ of patients $[6,42]$. Failure to address infusion site pain may lead to discontinuation of treatment [6,42]. Although site pain is not dose-dependent [65] and is manageable in the majority of patients, local, topical or systemic analgesics may be required [39]. 
Patients with chronic pain may need referral to a pain specialist. HCPs should consider dry siting of the infusion cannula before the drug is given to allow the patient to get used to the cannula, which itself can be painful [49].

Localised abscess formation at infusion sites may occur [39] and a lack of suitable sites may become an issue with chronic use. Patients who are on s.c. treprostinil for 10 years or longer may have skin hardening and no suitable areas to place the catheter. There is scope for flexibility with regard to how frequently the site is changed. Historically, it was suggested that the site should be changed every 3-4 days [49, 65]. However, in current practice, the site does not have to be changed so frequently $[49,66]$. As treprostinil can cause significant site pain, which abates after several days, patients often use the same site for weeks or months [67], providing the tissue at the infusion site remains healthy.

Patients, carers and HCPs should be aware of the possibility of infusion system malfunctions. These can lead to adverse events related to symptoms of excess treprostinil, such as nausea, or drug interruption, resulting in a return of PAH symptoms such as dyspnoea [6]. Although these events are uncommon in clinical practice, patients are advised to carry a spare pump, drug vials, necessary consumables and the emergency contact details of their pulmonary hypertension centre at all times.

\section{Inhaled administration}

Treprostinil $[8,68]$ and iloprost $[9,10]$ are inhaled agents for the treatment of PAH (table 1). The inhaled route avoids the need for s.c. or i.v. access and the pump delivery systems associated with the infusion of parenteral prostanoids [39], and reduces systemic side-effects [52, 69]. For patients who cannot manage a parenteral infusion, for example those with extensive digital ulcers and limited dexterity, inhaled agents may provide an alternative means of targeting the $\mathrm{PGI}_{2}$ pathway. Current ESC/ERS guidelines support the use of inhaled therapies for the treatment of WHO FC III or IV patients (table 1) [3, 17].

The use of inhaled therapies can be quite time-consuming as a result of the frequency and length of the inhalations, as well as the time required for drug preparation and device maintenance $[8-10,55,68]$. This may affect patient compliance, ultimately reducing the efficacy of the treatment. Inhaled treprostinil should be administered four times per day [8], with each inhalation taking up to 3 min [68]. Inhaled iloprost can be even more time consuming, requiring six to nine inhalations per day, with each inhalation taking between 4 and 10 min depending on the dose and nebuliser $[9,10]$. For both therapies, time must also be spent maintaining the nebuliser by cleaning it daily, with a more thorough clean on a weekly basis [10, 68]. For iloprost, the drug chamber must also be rinsed after every use. A number of practical steps can be taken to aid in the use of inhaled therapies (table 3). Of particular importance is detailed education on the mode of administration, including teaching patients how to use and look after the devices correctly. Written support materials including brochures and tools to aid compliance are also useful. Patients may set up medication reminders through alarms or apps on their smartphones. Pulmonary hypertension centres may use InSight training devices to reinforce effective breathing patterns and check adherence [50].

Inhaled therapies may cause side-effects related to the route of administration, including cough, throat irritation, pharyngolaryngeal pain and risk of bronchospasm [8-10]. As they are not administered continually, patients are not dosed overnight, which is likely to result in sub-efficacious plasma drug levels while sleeping.

The risk of a rebound effect cannot be excluded in case of interruption of inhaled therapies [9]. Therapy should be resumed as soon as possible [8] and an alternative treatment considered in critically ill patients [9]. Providing patients with a back-up device will help in case device malfunction occurs [8].

\section{Oral administration}

Oral therapies that target the $\mathrm{PGI}_{2}$ pathway (table 1) were developed to address the challenges associated with the other routes of administration. Currently, there are three approved oral drugs: beraprost (only approved in Japan and South Korea) [14, 15, 24, 70]; treprostinil (only approved in the USA) [11]; and selexipag (approved in the USA, Europe and a number of other countries worldwide) [12, 13, 71]. Compared with most parenteral $\mathrm{PGI}_{2}$ therapies, these drugs have a relatively long half-life $[12,20,22]$. As these drugs have not been studied in WHO FC IV patients, the current ESC/ERS guidelines recommend the use of selexipag in WHO FC II and III patients as monotherapy or combination therapy, and state that beraprost and treprostinil may be considered in WHO FC III patients as monotherapy [3, 17] (table 1). In summary, oral therapies should therefore not be seen as substitutes for parenteral therapies in WHO FC IV patients.

Although oral administration is relatively simple compared with the parenteral routes, up-titration is still required. There also remains a need for comprehensive patient education to ensure that patients understand the function of the medication, the importance of regular dosing and what to do if a dose is late or missed. Patients treated with selexipag need to be informed that if they interrupt treatment for 3 days or longer, it is recommended that they restart at a lower dose and re-titrate [12, 13]. The risks of 
abruptly stopping parenteral therapy are well-recognised $[4,6,18]$. However, less is known about the impact of interrupting oral therapies that target the $\mathrm{PGI}_{2}$ pathway. Patients require advice on how to manage their drug regimen if they are going to be nil by mouth due to the need for surgery. In the event of a planned short-term treatment interruption for patients unable to take oral medications, temporary use of i.v., s.c. or inhaled therapies may be considered. A recent analysis from the phase III GRIPHON study with selexipag indicated that treatment interruption was generally manageable and well-tolerated [72]. After re-titration, most patients reached similar selexipag doses to those received prior to stopping treatment, indicating that treatment can be successfully restarted [72].

Although oral drugs are more convenient than other routes of administration, patients may neglect to take their tablets and compliance needs to be considered. Data from other disease areas show that compliance for orally administered therapies can be suboptimal [73-75] and it is likely that patients who need to take medication more frequently will be less compliant. HCPs should emphasise the need for medication compliance, and provide support to patients and their carers in order to maximise compliance and ensure that patients receive the full treatment benefits. As for inhaled therapies, patients may set up medication reminders through alarms on their smartphones.

\section{Conclusion}

A wealth of evidence exists on the benefits of therapies that target the $\mathrm{PGI}_{2}$ pathway in $\mathrm{PAH}$. These agents have a good risk-benefit profile and provide significant therapeutic benefits to patients. However, administration is not necessarily straightforward due to the need for titration and considerations regarding route of administration. An important aspect of optimising the use of these therapies is to address the practical challenges associated with their use. Practical advice and support delivered in a timely manner helps patients to overcome their concerns about treatment. With an effective management plan and support from an experienced multidisciplinary team, dealing with the complexities of therapies that target the $\mathrm{PGI}_{2}$ pathway becomes more manageable.

\section{Acknowledgements}

The authors would like to thank Kat Karolemeas (nspm Ltd, Meggen, Switzerland) for medical writing assistance, funded by Actelion Pharmaceuticals Ltd (Allschwil, Switzerland).

\section{References}

1 Tuder RM, Cool CD, Geraci MW, et al. Prostacyclin synthase expression is decreased in lungs from patients with severe pulmonary hypertension. Am J Respir Crit Care Med 1999; 159: 1925-1932.

2 Christman BW, McPherson CD, Newman JH, et al. An imbalance between the excretion of thromboxane and prostacyclin metabolites in pulmonary hypertension. N Engl J Med 1992; 327: 70-75.

3 Galiè N, Humbert M, Vachiery JL, et al. 2015 ESC/ERS Guidelines for the diagnosis and treatment of pulmonary hypertension: The Joint Task Force for the Diagnosis and Treatment of Pulmonary Hypertension of the European Society of Cardiology (ESC) and the European Respiratory Society (ERS): Endorsed by: Association for European Paediatric and Congenital Cardiology (AEPC), International Society for Heart and Lung Transplantation (ISHLT). Eur Heart J 2016; 37: 67-119.

4 Barst RJ, Rubin LJ, Long WA, et al. A comparison of continuous intravenous epoprostenol (prostacyclin) with conventional therapy for primary pulmonary hypertension. N Engl J Med 1996; 334: 296-302.

5 McLaughlin VV. Medical management of primary pulmonary hypertension. Expert Opin Pharmacother 2002; 3: 1-7.

6 Remodulin (treprostinil). US Prescribing Information, December 2014. www.remodulin.com/downloads/remodulinprescribinginformation.pdf Date last accessed: November 2016.

7 Ilomedin (iloprost). Data sheet, March 2012. www.medsafe.govt.nz/profs/datasheet/i/Ilomedininf.pdf Date last accessed: November 2016.

8 Tyvaso (treprostinil). US Prescribing Information, June 2016. www.accessdata.fda.gov/drugsatfda_docs/label/2016/ 022387s014lbl.pdf Date last accessed: November 2016.

9 Ventavis (iloprost). Summary of Product Characteristics, December 2014. www.ema.europa.eu/docs/en_GB/ document_library/EPAR_-_Product_Information/human/000474/WC500048691.pdf Date last accessed: November 2016.

10 Ventavis (iloprost). US Prescribing Information, November 2013. www.accessdata.fda.gov/drugsatfda_docs/label/ 2013/021779s014lbl.pdf Date last accessed: November 2016.

11 Orenitram (treprostinil). US Prescribing Information, January 2016. www.orenitram.com/pdf/Orenitram_Full_ Prescribing_Information.pdf Date last accessed: November 2016.

12 Uptravi (selexipag). Summary of Product Characteristics, May 2016. www.ema.europa.eu/docs/en_GB/document_ library/EPAR__Product_Information/human/003774/WC500207173.pdf Date last accessed: November 2016.

13 Uptravi (selexipag). US Prescribing Information, December 2015. www.accessdata.fda.gov/drugsatfda_docs/label/ 2015/207947s000lbl.pdf Date last accessed: November 2016.

14 Astellas Pharma Inc. Announcement of the Launch of the Pulmonary Arterial Hypertension Agent Careload ${ }^{\circ}$ LA Tablets $60 \mathrm{~g}$ in Japan. 2007. www.astellas.com/en/corporate/news/pdf/071218_eg.pdf Date last accessed: August 2016. Date last updated: December 2007.

15 RAD-AR Council Japan. DORNER Drug Information Sheet. 2016. www.rad-ar.or.jp/siori/english/kekka.cgi? $\mathrm{n}=32259$ Date last accessed: November 2016.

16 Lang IM, Gaine SP. Recent advances in targeting the prostacyclin pathway in pulmonary arterial hypertension. Eur Respir Rev 2015; 24: 630-641. 
17 Galiè N, Humbert M, Vachiery JL, et al. 2015 ESC/ERS Guidelines for the diagnosis and treatment of pulmonary hypertension. Eur Respir J 2015; 46: 903-975.

18 Flolan (epoprostenol). Summary of Product Characteristics, April 2015. www.medicines.org.uk/emc/medicine/7173 Date last accessed: November 2016.

19 Veletri (epoprostenol). Summary of Product Characteristics, October 2015. www.medicines.org.uk/emc/medicine/ 27734 Date last accessed: November 2016.

20 Veletri (epoprostenol). US Prescribing Information, July 2016. wwwl.actelion.us/documents/us/productdocumentation/veletri-(epoprostenol-for-injection)-prescribing-information.pdf Date last accessed: November 2016.

21 UK Medicines Information. New Drugs Online Report for treprostinil sodium 2016. www.ukmi.nhs.uk/ applications/ndo/record_view_open.asp?newDrugID=3065 Date last accessed: July 2016.

22 Galiè N, PA C, Frost A. Updated treatment algorithm of pulmonary arterial hypertension. J Am Coll Cardiol 2013; 62: D60-D72.

23 Astellas Pharma Inc. Announcement of the Acquisition of Marketing Approval for the Pulmonary Arterial

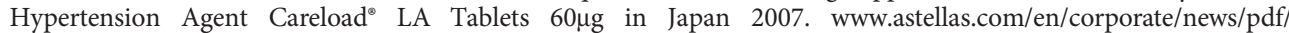
071022_eg.pdf Date last accessed: July 2016. Date last updated: October 2007.

24 Skoro-Sajer N, Lang IM. Selexipag for the treatment of pulmonary arterial hypertension. Expert Opin Pharmacother 2014; 15: 429-436.

25 Olschewski H, Rose F, Schermuly R, et al. Prostacyclin and its analogues in the treatment of pulmonary hypertension. Pharmacol Ther 2004; 102: 139-153.

26 Tyvaso (treprostinil). Patient Package Insert, May 2013. www.tyvaso.com/Content/dtc/pdf/Tyvaso-PPI.pdf Date last accessed: November 2016.

27 Farber HW, Miller DP, Meltzer LA, et al. Treatment of patients with pulmonary arterial hypertension at the time of death or deterioration to functional class IV: Insights from the REVEAL Registry. J Heart Lung Transplant 2013; 32: 1114-1122.

28 McLaughlin VV, Langer A, Tan M, et al. Contemporary trends in the diagnosis and management of pulmonary arterial hypertension: an initiative to close the care gap. Chest 2013; 143: 324-332.

29 Grünig E, Egenlauf B, Lange TJ, et al. Safety and tolerability of rapid dose-titration of subcutaneous (SC) treprostinil in pulmonary arterial hypertension (PAH). Eur Respir J 2015; 46: PA2114.

30 Sitbon $\mathrm{O}$, Channick R, Chin KM, et al. Selexipag for the treatment of pulmonary arterial hypertension. $N$ Engl J Med 2015; 373: 2522-2533.

31 Parikh KS, Rajagopal S, Fortin T, et al. Safety and tolerability of high-dose inhaled treprostinil in pulmonary hypertension. J Cardiovasc Pharmacol 2016; 67: 322-325.

32 Rajkumar R, Konishi K, Richards TJ, et al. Genomewide RNA expression profiling in lung identifies distinct signatures in idiopathic pulmonary arterial hypertension and secondary pulmonary hypertension. Am J Physiol Heart Circ Physiol 2010; 298: H1235-H1248.

33 Falcetti E, Hall SM, Phillips PG, et al. Smooth muscle proliferation and role of the prostacyclin (IP) receptor in idiopathic pulmonary arterial hypertension. Am J Respir Crit Care Med 2010; 182: 1161-1170.

34 Gatfield J, Menyhart K, Nayler O. Influence of IP receptor density on agonist activity of ACT-333679, the active metabolite of selexipag. Am J Respir Crit Care Med 2016; 193: A2239.

35 Jones A, Wang-Smith L, Pham T, et al. Pharmacokinetics of 3 times a day dosing of oral treprostinil in healthy volunteers. J Cardiovasc Pharmacol 2014; 63: 227-232.

36 White RJ, Frutiger K, Theuer A, et al. A pharmacokinetic and tolerability comparison in subjects transitioning from twice daily to three times daily dosing of oral treprostinil. Chest 2014; 146: 865A.

37 Chakinala MM, Feldman JP, Rischard F, et al. Transition from parenteral to oral treprostinil in pulmonary arterial hypertension. J Heart Lung Transplant 2016; in press [DOI: 10.1016/j.healun.2016.06.019].

38 United Therapeutics. Trial of the Early Combination of Oral Treprostinil With Background Oral Monotherapy in Subjects With Pulmonary Arterial Hypertension (FREEDOM-Ev). https://clinicaltrials.gov/ct2/show/NCT01560624 Date last accessed: August 2016. Date last updated: April 20, 2016

39 McLaughlin VV, Palevsky HI. Parenteral and inhaled prostanoid therapy in the treatment of pulmonary arterial hypertension. Clin Chest Med 2013; 34: 825-840.

40 Safdar Z. Treatment of pulmonary arterial hypertension: the role of prostacyclin and prostaglandin analogs. Respir Med 2011; 105: 818-827.

41 Skoro-Sajer N, Lang IM, Harja E, et al. A clinical comparison of slow- and rapid-escalation treprostinil dosing regimens in patients with pulmonary hypertension. Clin Pharmacokinet 2008; 47: 611-618.

42 Simonneau G, Barst RJ, Galie N, et al. Continuous subcutaneous infusion of treprostinil, a prostacyclin analogue, in patients with pulmonary arterial hypertension: a double-blind, randomized, placebo-controlled trial. Am J Respir Crit Care Med 2002; 165: 800-804.

43 Graarup J, Ferrari P, Howard L. Patient engagement and self-management in pulmonary arterial hypertension. Eur Respir Rev 2016; 25: 399-407.

44 Pulmonary Hypertension Association. Connect Online. 2016. www.phassociation.org/ConnectOnline Date last accessed: July 2016.

45 Archer-Chicko C. Nursing care of patients with pulmonary arterial hypertension. In: Yuan JXJ, Garcia JGN, Hales CA, et al., eds. Textbook of Pulmonary Vascular Disease. 1st Edn. Berlin, Springer Science+Business Media, 2011; pp. 1531-1558

46 Gin-Sing W. Pulmonary arterial hypertension: a multidisciplinary approach to care. Nurs Stand 2010; 24: 40-47.

47 Mubarak KK. A review of prostaglandin analogs in the management of patients with pulmonary arterial hypertension. Respir Med 2010; 104: 9-21.

48 Sitbon O, Delcroix M, Bergot E, et al. EPITOME-2: an open-label study assessing the transition to a new fomulation of intravenous epoprostenol in patients with pulmonary arterial hypertension. Am Heart J 2014; 167: 210-217.

49 Davis MB, Rubenfire M. Current and emerging therapies in pulmonary arterial hypertension: focus on treprostinil. Clin Med Rev Vasc Health 2011; 3: 39-52.

50 Dhand R. Intelligent nebulizers in the age of the Internet: the I-neb Adaptive Aerosol Delivery (AAD) system. J Aerosol Med Pulm Drug Deliv 2010; 23: Suppl. 1, iii-v. 
51 Flolan (epoprostenol). US Prescribing Information, June 2016. www.gsksource.com/pharma/content/dam/ GlaxoSmithKline/US/en/Prescribing_Information/Flolan/pdf/FLOLAN-PI-PIL.PDF Date last accessed: November 2016.

52 Badesch DB, McLaughlin VV, Delcroix M, et al. Prostanoid therapy for pulmonary arterial hypertension. $J$ Am Coll Cardiol 2004; 43: 56S-61S.

53 Burger CD, Long PK, Shah MR, et al. Characterization of first-time hospitalizations in patients with newly diagnosed pulmonary arterial hypertension in the REVEAL registry. Chest 2014; 146: 1263-1273.

54 Actelion Pharmaceuticals Ltd. A holistic approach to patient care in pulmonary arterial hypertension 2016. www. phaeurope.org/wp-content/uploads/Holistic-Care-in-PAH-report-FINAL-25.01.16.pdf Date last accessed: July 2016. Date last updated: January 2016

55 Humbert M, Sitbon O, Simonneau G. Treatment of pulmonary arterial hypertension. N Engl J Med 2004; 351 : $1425-1436$.

56 Goudet V, Timsit JF, Lucet JC, et al. Comparison of four skin preparation strategies to prevent catheter-related infection in intensive care unit (CLEAN trial): a study protocol for a randomized controlled trial. Trials 2013; 14: 114.

57 Dezfulian C, Lavelle J, Nallamothu BK, et al. Rates of infection for single-lumen versus multilumen central venous catheters: a meta-analysis. Crit Care Med 2003; 31: 2385-2390.

58 Templeton A, Schlegel M, Fleisch F, et al. Multilumen central venous catheters increase risk for catheter-related bloodstream infection: prospective surveillance study. Infection 2008; 36: 322-327.

59 Ivy DD, Calderbank M, Wagner BD, et al. Closed-hub systems with protected connections and the reduction of risk of catheter-related bloodstream infection in pediatric patients receiving intravenous prostanoid therapy for pulmonary hypertension. Infect Control Hosp Epidemiol 2009; 30: 823-829.

60 Doran AK, Ivy DD, Barst RJ, et al. Guidelines for the prevention of central venous catheter-related blood stream infections with prostanoid therapy for pulmonary arterial hypertension. Int J Clin Pract 2008; 160: 5-9.

61 Akagi S, Matsubara H, Ogawa A, et al. Prevention of catheter-related infections using a closed hub system in patients with pulmonary arterial hypertension. Circ J 2007; 71: 559-564.

62 Widlitz AC, McDevitt S, Ward GR, et al. Practical aspects of continuous intravenous treprostinil therapy. Crit Care Nurse 2007; 27: 41-45, 47.

63 Furiasse NM, Rich JD. Contemporary pharmacotherapies involving nitric oxide, prostacyclin, and endothelin receptor signaling pathways. In: Maron BA, Zamanian R, Waxman AB, eds. Pulmonary Hypertension: Basic Science to Clinical Medicine. Cham, Springer International Publishing, 2016; pp. 257-270.

64 Peacock A, Naeije R, Rubin L, eds. Pulmonary Circulation: Diseases and Their Treatment. 4th Edn. Boca Raton, CRC Press, 2016.

65 Gomberg-Maitland M, Preston IR. Prostacyclin therapy for pulmonary arterial hypertension: new directions. Semin Respir Crit Care Med 2005; 26: 394-401.

66 Levy M, Celermajer DS, Bourges-Petit E, et al. Add-on therapy with subcutaneous treprostinil for refractory pediatric pulmonary hypertension. J Pediatr 2011; 158: 584-588

67 White RJ, Levin Y, Wessman K, et al. Subcutaneous treprostinil is well tolerated with infrequent site changes and analgesics. Pulm Circ 2013; 3: 611-621.

68 Tyvaso (treprostinil). Tyvaso Patient Brochure 2013. www.tyvaso.com/pdf/Tyvaso_Patient_Brochure.pdf Date last accessed: November 2016.

69 LeVarge BL. Prostanoid therapies in the management of pulmonary arterial hypertension. Ther Clin Risk Manag 2015; 11: 535-547.

70 Pharmaceuticals and Medical Devices Agency. Pharmaceuticals and Medical Devices Safety Information 2008. www.pmda.go.jp/files/000153860.pdf Date last accessed: August 2016. Date last updated: January 2008.

71 Actelion Pharmaceuticals Ltd. Uptravi Product Availability and Regulatory Status. 2016. www.actelion.com/ documents/corporate/fact-sheets/product-availability/product-availability-uptravi.pdf Date last accessed: July 2016. Date last updated: July 2016.

72 Preston IR, Chin K, Di Scala L, et al. Management of selexipag interruptions in the GRIPHON study. Eur Respir J 2016; 48: Suppl. 60, PA1870.

73 Barillet M, Prevost V, Joly F, et al. Oral antineoplastic agents: how do we care about adherence? Br J Clin Pharmacol 2015; 80: 1289-1302.

74 Tadic D, Spasojevic IB, Tomasevic ZI, et al. Oral administration of antineoplastic agents: the challenges for healthcare professionals. J BUON 2015; 20: 690-698.

75 Brynhildsen J. Combined hormonal contraceptives: prescribing patterns, compliance, and benefits versus risks. Ther Adv Drug Saf 2014; 5: 201-213. 